\title{
A Literature Review of Internal Control of Colleges and Universities in China
}

\author{
Wei-guo KANG \\ Finance Department of Nanjing University of Finance and Economics, Nanjing, China
}

Keywords: University Internal Control; Risk Assessment; Countermeasures.

\begin{abstract}
With the further advancement of educational reform, the management of universities is also becoming more and more complicated, so it is crucial to strengthen the internal control in Chinese universities. Based on the existing literature, this paper analyzes the elements and characteristics of internal control, and puts forward the problems existing in internal control in Chinese universities from three aspects of internal control environment, internal control risk management and internal control activities. Finally, this paper proposes suggestions for the internal control management of universities in China from five aspects: improving the internal control system, establishing risk early-warning and assessment mechanism, strengthening the implementation and supervision, strengthening the construction of control environment and perfecting the evaluation mechanism of internal control.
\end{abstract}

\section{Introduction}

Internal control plays an important role in the process of modern management in colleges and universities. To some extent, university management can achieve self-regulation and self-restriction under the coordination of internal control. Once the internal control fails to perform its functions, it may cause great losses to colleges and universities. At present, universities generally have a weak awareness of internal control, which lacks effectiveness. In addition, the imperfect construction of internal control system leads to the lack of risk prevention capabilities, which causes the slow and immature process of internal control work in universities. Therefore, based on the literature of internal control in universities at home and abroad, this paper tries to explore its development trend and problems thus laying a theoretical foundation to better perfect the internal control system, and improving the scope and depth of internal control research in colleges and universities in China.

\section{Construction of Internal Control Elements in Colleges and Universities}

The research on internal control abroad is earlier than that in China, and the research results are more mature. Throughout the foreign literature, there are three influential internal control frameworks: the US COSO Internal Control Report, Canadian COCO Report, and UK CADBURY Report [1]. These three reports describe the internal control elements and objectives. The COSO internal control report points out five major elements, namely, control environment, risk assessment, control activities, information and communication, and monitoring [2]. The COCO report divides internal control elements into 6 aspects which are resources, systems, processes, culture, structures and tasks. Three reports systematically identify the control objectives. Although different, they all include efficiency, reliability and effectiveness.

The internal control of foreign universities is mainly based on the above three reports. Developed countries, such as the United States, Japan, and the United Kingdom, attach great importance to the application of internal control in universities, especially the improvement of internal control systems and the control of risks. Domestic scholars are relatively lagging behind in the study of internal control in colleges and universities. In the early period, they mainly focused on internal accounting controls. With the increasingly clear concept and extension of internal control, they have gradually enriched their perspectives on the internal control of universities.

With the application of Marxist materialism methodology, Zhao Hongwei (2015) divided the internal control in universities into four basic categories: concept, activities, systems and control 
mechanisms. In view of these four categories, with the concept of internal control as its core, the application of information technology in internal control as its guarantee, he constructed an internal control system suited to the features of universities in China so as to promote internal control in universities effectively [3]. Chen Liuping, Wei Wei and Zhang Mengchao (2014) designed a questionnaire based on an investigation of colleges and universities in Jiangsu according to the five elements identified by COSO report. They held that internal control system should take environmental control as the priority, then focus on the control of economic activities such as projects and assets, and coordinate the interaction between economic contract management and budget control. They also emphasized the important role of information technology in internal control system. Various controls should be internalized into the information system of the university so as to combine the procedure of internal control and the information technology [4]. Liu Zhengbing (2013) made a research on the construction of internal control framework in universities based on financial risk management and control. He pointed out that financial risk had become a key factor which restricted the development of universities [5]. Similarly, on the basis of the contents and objectives of internal control, Huang Tao (2015) also believed that financial management was one of the important contents of internal control in colleges and universities. It was necessary to strengthen financial management and supervision to improve the efficiency of funding use [6]. From the perspective of internal control evaluation, Wang Weixing and Zhao Gang (2008) put forward that the primary task of the internal control system of universities was to construct the elements of the internal system [7]. In order to establish a perfect internal control system, Liu Yanping, Zheng Xiaodong and Li Chenru (2015) viewed the information construction as the prominent feature of the perfect management of modern universities [8].

\section{Characteristics of Internal Control in Colleges and Universities}

\subsection{Wider range}

With the diversification of the management of universities in China, the internal control has been endowed with the connotation of the times, covering a wider range. Internal control includes not only the control of schools themselves, but also that of economic activities of institutions that cooperate with universities, such as the cooperation between textbooks and press, between colleges and hospitals, between colleges and property management, or cooperation between colleges and design institutes and other scientific research institutions. However, in terms of the situation of internal control in Chinese universities, the examination and approval procedures are not rigorous enough in the economic cooperation with these institutions, leading to serious corruption. Therefore, universities should strengthen supervision and establish a perfect internal control system.

\subsection{More complicated accounting}

In the process of internal control, accounting, as the principal business of universities, should follow the Accounting Regulations for Institutions of Higher Learning. In addition, some subsidiary units cooperating with universities are independent accounting entities. Although they serve universities, in essence, they are enterprises, so the accounting should follow the Accounting Standards for Business Enterprises. Therefore, the accounting involved in the internal control of universities is more complex, which also increases the difficulty of control management and makes the internal control system more complicated.

\subsection{More diverse sources and uses of funds}

With the development of China's education reform, the economic source of universities for their daily activities is no longer solely dependent on government funding, but also on the social donations and investment income of university funds. There is a variety of sources for social donations, including the financial support provided by enterprises for scientific research and the funds donated by alumni, etc. The funds are also widely used in purchasing teaching related equipment, supporting teachers and students in scientific research and so on. The diversity of the 
sources and uses of funds requires universities to establish the internal control system and constantly improve it.

\section{Present Situation and Existing Problems of Internal Control in Colleges and Universities}

Although China has established a relatively complete internal control policy in universities, many out-of-control events have exposed the drawbacks of internal control. Chang Qing and Shen Youdi (2016) used questionnaires to investigate the implementation of internal control in 21 colleges and universities in Jiangsu province [9]. In light of the COSO report, the obstacles to the implementation of internal control standards were analyzed and it was found that many problems existed in internal control of universities. For example, the organizational structure is not reasonable; the system is incomplete; the establishment and implementation of risk assessment mechanisms are deficient; the budget control is not scientific; the government procurement is not standardized; the control of revenue and expenditures needs to be improved; the asset control is slightly insufficient; and the infrastructure projects are not sufficiently controlled; contract management and financial reporting control are not perfect; and information and communication have many deficiencies. They proposed some solutions, namely optimizing the internal control environment, standardizing control activities, improving risk assessment, improving information and communication, and strengthening the supervision. Throughout the literature at home and abroad, the analysis of the present situation and existing problems of internal control in universities mainly focuses on the following aspects:

\subsection{Present situation and existing problems of control environment}

(1) The internal organizational structure is not perfect. Some universities adopt the unitary structure. And school leaders are appointed, who have different duties. However, there is a lack of supervision over the deliberation and notification of important issues in schools through relevant regulations. Most colleges and universities have established decision-making and supervision departments such as the association of collegiate leadership and the party committee. At present, the institutional construction is being further improved to ensure the exercise of university power in accordance with the law.

(2) There is a weak awareness of internal control in universities. The phenomena of weak consciousness, poor execution, combination of incompatible jobs, and empty internal financial control still exist in universities. Wang Chaohui and Sun Zhinan (2016) pointed out that the drawbacks of internal control in universities were mainly manifested in the benefit level, official standard and hierarchical management mechanism [10]. The effective way to eliminate the drawbacks was to further guide the universities to establish the concept of modern governance to improve the operational mechanism of internal control.

\subsection{Present situation and existing problems of risk management}

The main risks faced by universities are the external environment and internal management. The external environmental risks refer to the competition with universities at home and abroad in an increasingly fierce competition environment, including graduate employment and school reputation, etc.

(1) Financial risks. Recently, the prevailing financial risks in colleges and universities are mostly due to the failure to repay the debts or the shortage of funds caused by enrollment expansion and relocation, as well as the incomplete accounting information and the illegal use of funds brought by the vacant internal management and improper financial management.

(2) Operational management risks. In view of the wide range of business activities, the operational management risks may exist in many aspects of university management activities, mainly including the risk of cadres' clean administration, low level of students, the declining teaching level, the campus public safety, inadequate schooling conditions, executive control, and academic corruption. 


\subsection{Present situation and existing problems of control activities}

(1) Budget management. The current budget of universities is relatively complete. Schools' various incomes should be uniformly accounted for and managed. Specifically, the finance office allocates the budget targets according to the annual budget and internal annual income and expenditure approved by the department of finance. However, over-expenditure or budget imbalance often appears in the internal management of universities. For example, funds for "special construction projects" and "other temporary projects" are unequally allocated or incorrectly defined.

(2) Information and communication. Information and communication is a process in which universities collect all information related to school operations in a timely and accurate manner and implement it with appropriate channels. It is the bridge for the interconnection of various elements of the university internal control framework system. At present, the internal information system of universities is gradually improved, and more and more universities make rational and full use of this bridge, but there are still some problems such as inaccurate information notification, inaccurate information processing, communication obstacles and so on. The information and communication system still needs to be further improved to promote the orderly development of internal control activities in universities.

\section{Countermeasures to Strengthen Internal Control in Colleges and Universities}

At present, there are many problems that directly or indirectly affect the development and goal realization of colleges and universities. One of the ways to solve these problems is to realize the transformation and innovation of internal control as soon as possible. Professor Shen Lie (2010), Institute of Internal Control, Zhongnan University of Economics and Law, thought that the best countermeasure was the transformation of internal control from traditional to comprehensive risk management. To achieve this goal, universities must strengthen the coordination and innovation of campus culture, risk control, and supervision systems [11]. In terms of financial management, Cai Xuehui (2013) conducted a study which showed that it lacked specific and feasible normative documents for internal management in Chinese universities. And the financial management staff had a weak awareness of internal control, and management regulations were not scientific as well [12]. In order to strengthen the internal control, colleges and universities should pay more attention to the financial management. The primary task is to improve the internal control regulations and system. Besides, it is necessary to raise awareness of the internal control of teaching staff, and to strengthen the overall quality of finance and accounting personnel, and finally, to grasp the key points of financial management and control. Therefore, on the basis of the existing literature, this paper proposes the following suggestions on how to strengthen the internal control in colleges and universities.

\subsection{To improve the construction of internal control system}

(1) To improve the budget management system. The budget management aims to coordinate all resources and make reasonable arrangements and plans for the funds of the school in the next year through some predictions. Colleges and universities should continue to explore new budgeting methods that are suitable for them, and break through the traditional mode of "zero-base budget" and "incremental budget".

(2) To improve the purchasing management system. Purchase should focus on the cost-benefit principle and reduce costs as much as possible on the premise of quality and quantity. Purchase payment is the weakest link in the internal control system in universities. Therefore, it is necessary to strengthen supervision over the purchasing process. For large-scale purchases, it has to call for bids and ensure the transparency of the bidding process. The financial department shall pay for the purchase items in accordance with the approval and the contract. The asset management department should pay attention to the quality and after service of the purchased goods.

(3) To improve the contract management system. Colleges and universities should strengthen the formulation, implementation, alteration and dissolution of contracts, especially the supervision of 
the content of the contract, and also strengthen the investigation of the contract parties' credit and performance.

\subsection{To establish risk early-warning and assessment mechanism}

With the diversification of the sources and uses of funds, colleges and universities no longer solely depend on government funding, but are responsible for their own management decisions, profits and losses, facing more and more risks which mainly include the operational risk and financial risk. Therefore, colleges and universities should establish risk early-warning and assessment mechanism, so as to combine prevention and assessment. Schools can set up a special risk assessment department, through qualitative and quantitative data analysis, to judge the probability and severity of internal control risk, strengthen the analysis, identification and response of the risks, reasonably control the operational and financial risks of universities, and constantly improve the internal control mechanism.

\subsection{To strengthen the implementation and supervision of internal control}

In the process of the implementation of internal control, staff should clearly define their respective responsibilities and strictly follow the rules and regulations. At the same time, the implementation process must be inspected and supervised. Once appears improper implementation, it must be seriously handled without committing irregularities.

In order to solve the problems of serious administrative intervention and imperfect supervision mechanism of internal control, colleges and universities can shift down the focus of internal control and expand the autonomy of grass-roots participation in university governance. Meanwhile, they can establish the board of supervisors and elect representatives of teaching staff and students as supervisors to participate in school governance, so as to strengthen the supervision of the internal control system of colleges and universities. In addition, the internal control system should strictly follow the principle of "separation of incompatible positions" to ensure a clear division of duties among different positions, so as to ensure mutual constraint and supervision among various departments, thus improving the internal control system in Chinese universities.

\subsection{To emphasize the construction of internal control environment}

The internal control environment in colleges and universities is seen as an important barometer for the internal control system to play its role. A good internal control environment can not only improve the efficiency of internal control, but also promote the establishment and improvement of internal control system. It mainly depends on the preferences and values of each participant. Therefore, it is necessary to improve the professional and moral quality of participants. All participants should abide by the laws and the school's regulations, and continuously improve their ideological and moral level, to prevent the occurrence of corruption. At the same time, more attention should be paid to the improvement of professional quality of participants in internal control. When selecting managers, colleges and universities must focus on their knowledge and skills. After employed, they have to take regular training so that they can constantly update their knowledge and improve their work skills and work efficiency, thus creating a good internal control environment.

\subsection{To improve the evaluation mechanism of internal control}

The evaluation of internal control in universities includes not only internal audit but also external evaluation. At present, the evaluation mechanism of internal control is not perfect and the internal audit institutions lack independence. Therefore, colleges and universities should take some measures to ensure the independence of internal audit department; at the same time, an audit committee should be established to strengthen the guidance and supervision of the internal audit department, so as to ensure the effectiveness of the design and operation of the internal control system. In addition, qualified colleges and universities can regularly hire accounting firms to conduct external audits of their financial conditions to identify the level of financial risks which can provide adequate and reasonable guarantees, thus preventing corruptions. 


\section{Acknowledgement}

This research was financially supported by the Project of Nanjing University of Finance and Economics "Research on the Accounting and Application of Digital Assets in Colleges and Universities".

\section{References}

[1] S.C. Rice, D.P. Weber. How Effective Is Internal Control Reporting under SOX 4047 Determinants of the Disclosure of Existing Material Weaknesses. Journal of Accounting Research, 2012, pp. 811-843.

[2] COSO. Internal Control Integrated Framework Guidance on Monitoring Internal Control Systems [R]. 2009.

[3] H.W., Zhao. Basic Categories and Framework Construction of Internal Control in Universities. Auditing Research, Vol. (3), 2015, pp. 108-112.

[4] L.P., Chen, W., Wei, and M.C., Zhang. Establishment of an Internal Control System in China's Institutions of Higher Learning: A Study Based on an Investigation of Colleges and Universities in Jiangsu Province. Journal of Higher Education Management, Vol. 8 (1), 2014, pp. 29-35.

[5] Z.B., Liu. Research on the Construction of Internal Control Framework in Universities Based on Financial Risk Management and Control. Journal of Soochow University (Philosophy and social science Edition), Vol. 34 (2), 2013, pp. 120-124.

[6] T., Huang. Discussion on Internal Control of Financial Management in University. Journal of Central University of Finance \& Economics, Vol. (S2), 2015, pp. 55-62.

[7] W.X., Wang and G., Zhao. A Research into the Construction and Application of the Model for Internal Control Evaluation of the Institutions of Higher Learning. Journal of Audit \& Economics, Vol. 23 (6), 2008, pp. 93-97.

[8] Y.P., Liu, X.D., Zhen and C.R., Li. Construction of the Fine Management System of Internal Control in Chinese Universities. China Higher Education, Vol. (10), 2015, pp. 32-34.

[9] Q., Chang and Y.D., Shen. Obstacles and Countermeasures of Internal Control Standards in Colleges and Universities. Journal of Soochow University (Philosophy and social science Edition), Vol. 37 (6), 2016, pp. 122-128.

[10] C.H., Wang and Z.N., Sun. The Present Situation, Disadvantages and Breakthrough of Internal Control in Colleges and Universities. Education Review, Vol. (5), 2016, pp. 56-59.

[11] L., Shen. On Transition and Innovation of University Internal Control. Journal of Higher Education, Vol. 31 (12), 2010, pp. 68-72.

[12] X.H., Cai. On the Financial Management at Universities from the Perspective of the Internal Control. Journal of Nanjing Audit University, Vol. 10 (3), 2013, pp. 104-110. 